\title{
Jeotermal Suların Uygulama Alanları ve Çevresel Problemler
}

\author{
Saadet Acar ${ }^{1 *}$, Hasan Köseoğlu ${ }^{2}$ \\ 1* Süleyman Demirel Üniversitesi, Mühendislik Fakültesi, Çevre Mühendisliği Bölümü, Isparta, Türkiye, (ORCID: 0000-0001-6685-4736), saadetacar32@,gmail.com \\ ${ }^{2}$ Süleyman Demirel Üniversitesi, Mühendislik Fakültesi, Çevre Mühendisliği Bölümü, Isparta, Türkiye (ORCID: 0000-0003-0183-208X), hasankoseoglu@sdu.edu.tr
}

(1st International Conference on Applied Engineering and Natural Sciences ICAENS 2021, November 1-3, 2021)

(DOI: 10.31590/ejosat.999121)

ATIF/REFERENCE: Acar, S. \& Köseoğlu, H. (2021). Jeotermal Suların Uygulama Alanları ve Çevresel Problemler. Avrupa Bilim ve Teknoloji Dergisi, (28), 325-332.

$\ddot{O} \mathbf{z}$

Günümüzde artan enerji ihtiyacı, fosil yakıtların yenilenememesi, maliyet, olumsuz çevresel ve atmosferik etkiler nedeniyle yenilenebilir enerji kaynaklarına yönelim artmaktadır. Hidroelektrik, rüzgar, güneş, jeotermal, dalga ve biyokütle kaynakları yenilenebilir enerji kaynakları olarak sınıflandırılmaktadır. Jeotermal enerji, çevreci ve yenilenebilir yapısının yanında farklı kullanım alanlarına uygunluğu nedeni ile alternatif olarak öne çıkmaktadır. Jeotermal kaynakların çok çeşitli ve geniş kullanım alanları olmasıyla birlikte başlıca kullanım uygulamaları; elektrik üretimi, merkezi ısıtma ve soğutma, meyve ve sebzelerin kurutulması, sera ve toprak 1sıtılması, su ürünleri yetiştiriciliği, yüzme, banyo ve sağlık amaçlı kullanımlardır. Jeotermal sistemlerin çoğu yüksek sıcaklık, basınç, buhar ve jeotermal akışkanları içermektedir. Jeotermal akışkanların bileşimleri lityum (Li), bor (B), arsenik (As), kalsiyum $\left(\mathrm{Ca}^{2+}\right)$, magnezyum $\left(\mathrm{Mg}^{2+}\right)$, demir $(\mathrm{Fe})$, sülfat $\left(\mathrm{SO}_{4}{ }^{2-}\right)$ ve klorür $\left(\mathrm{Cl}^{-}\right)$gibi çeşitli bileşenlerden oluşmaktadır. Ayrıca jeotermal buhar belirli miktarda cıva, hidrojen sülfür, amonyak, metan ve radon gibi elementleri de içerebilmektedir. Bunun yanı sıra jeotermal sulardaki bor, arsenik ve lityum gibi elementler insan sağlığı, tarım arazileri ve su ortamları için çeşitli olumsuz etkilere neden olmaktadır. Bu tip içeriklere sahip olan jeotermal sular, alıcı ortamlara deşarj edildiklerinde sucul yaşam, sulama suyu ve içme suyu üzerinde toksik çevresel etkilere sahiptir. Bu sebeple, jeotermal suların çeşitli yöntemlerle arıtılması gerekmektedir. Jeotermal akışkanın kimyasal özelliklerine bağlı olarak karşılaşılan sorunlardan bir diğeri de, orta ve yüksek sıcaklıktaki jeotermal sistemlerdeki tortulaşma ve korozyon problemleridir. Silika $\left(\mathrm{SiO}_{2}\right)$, jeotermal enerji santrallerinde tortulaşmaya sebep olan ana bileşendir. Karbondioksit $\left(\mathrm{CO}_{2}\right)$ varlığında oluşan korozyon ise, jeotermal sistemlerde en çok karşılaşılan durumlardan biridir. Bu çalışmada, jeotermal suların kimyasal özellikleri, uygulama alanları ve çevresel problemleri değerlendirilmiştir.

Anahtar Kelimeler: Çevresel Etki, Jeotermal Enerji, Jeotermal Su, Sürdürülebilirlik, Tortulaşma

\section{Application Areas of Geothermal Waters and Environmental Problems}

\begin{abstract}
Today, the trend towards renewable energy sources is increasing due to the increasing energy demand, non-renewable fossil fuels, costs, negative environmental and atmospheric effects. Hydroelectric, wind, solar, geothermal, wave and biomass sources are classified as renewable energy sources. Geothermal energy stands out as an alternative due to its environmentally-friendly and renewable nature, as well as its suitability for different usage areas. Although geothermal resources have a wide range of uses, the main usage applications are; electricity generation, central heating and cooling, drying of fruits and vegetables, greenhouse and soil heating, aquaculture, swimming, bathing and health purposes. Most of these systems involve high temperature, pressure, steam and geothermal fluids. The compositions of geothermal fluids consist of various components such as lithium (Li), boron (B), arsenic (As), calcium (Ca ${ }^{2+}$ ), magnesium $\left(\mathrm{Mg}^{2+}\right)$, iron $(\mathrm{Fe})$, sulfate $\left(\mathrm{SO}_{4}{ }^{2-}\right)$, and chloride $\left(\mathrm{Cl}^{-}\right)$. In addition, geothermal steam may contain certain amounts of elements such as mercury, hydrogen sulfide, ammonia, methane and radon. Also, elements such as boron, arsenic and lithium in geothermal waters cause various negative effects on human health, agricultural lands and aquatic environments. Geothermal waters, which have various contents, may have toxic environmental effects on aquatic life, irrigation water and drinking water when they discharged into receiving environments. For this reason, it is necessary to treat geothermal waters by various methods. Another problem encountered depending on the chemical properties of the geothermal fluid is scaling and corrosion problems in medium and high temperature geothermal systems. Silica $\left(\mathrm{SiO}_{2}\right)$ is the main component that causes scaling in geothermal power plants. Corrosion in the presence of carbon dioxide $\left(\mathrm{CO}_{2}\right)$ is one of the most common situations in geothermal systems. In this study, the chemical properties, application areas and environmental problems of geothermal waters were evaluated.
\end{abstract}

Keywords: Environmental Impact, Geothermal Energy, Geothermal Water, Scaling, Sustainability

* Sorumlu Yazar: saadetacar32@gmail.com 


\section{Giriş}

Hızla büyüyen dünya nüfusu ve giderek artan çevresel problemlerle birlikte sürdürülebilir kalkınma, insanlık için çok önemli bir konu haline gelmiştir (Hepbasli ve Ozgener, 2004). Bu bağlamda enerji; toplum, ekonomi ve çevre için en önemli konulardan biri olarak görünmektedir (Dincer ve Ozcan, 2018). Enerji sorunlarının azaltılmasına yönelik bir yaklaşım, geleneksel fosil yakıt teknolojilerinin yerine yenilenebilir enerji kaynaklarının getirilmesidir (Anderson ve Rezaie, 2019). Yenilenebilir enerji kaynakları; sera gazının azaltılması, enerjinin kendi kendine yeterliliği ve yerel ekonomilerin gelişimi gibi faydalar sağlama konusunda önemli bir potansiyele sahiptir (Hondo ve Moriizumi, 2017). Petrol, kömür, nükleer enerji gibi kendini yenileme durumu olmayan kaynakların bilinçsizce kullanılması ve buna bağlı olarak enerji kaynaklarının hızla tükenmeye başlaması yenilenebilir enerji kaynaklarını önemli hale getirmiştir (Külekçi, 2010). Bu enerji kaynakları; jeotermal, hidrolik, kimyasal, nükleer, mekanik (potansiyel ve kinetik), termal (1s1l), güneş, rüzgar gibi değişik şekillerde bulunabilmektedir (Koç ve Şenel, 2013). Yenilenebilir enerji kaynakları arasında olan jeotermal enerji, alternatif ve sürdürülebilir bir enerji kaynağı olarak görülmektedir (Anderson ve Rezaie, 2019). Jeotermal enerji; stabil, operasyonel olarak güvenli, çevre dostu, düşük sera gazı emisyonlarına ve uzun dönemli uygulama tecrübesine sahip olması nedeniyle önemli bir potansiyele sahiptir (Shortall vd., 2015). Bu kaynaklar, diğer yenilenebilir enerji kaynakları ile karşılaştırıldığında, büyük rezervlere ve yüksek kullanım verimliliğine sahiptir ( $\mathrm{Li} \mathrm{vd.,}$ 2015). Jeotermal enerji, yeraltında depolanan isı enerjisidir. Yer kabuğunun farklı derinliklerinde biriken 1sı, çeşitli yer altı ve yer üstü sularına göre daha fazla tuz, mineral ve gazlar içeren sıcak su ve buhardır (Aydıngöz, 2005). Bu kaynaklar genel olarak, aktif kırık sistemleri ile volkanik ve magmatik alanların etrafında oluşmaktadır (Yanar, 2015). Bu alanlar, jeotermal enerjinin varlığından yararlanırken, aynı zamanda volkanik patlama riskine de dayanmaktadır (Soelaiman, 2016).

Jeotermal rezervuarlar, enerji üretiminin taleplerini karşılamak için kullanılan, buhar, sıcak su veya her ikisinin karışımdan oluşan jeotermal alanlardır (Toth ve Bobok, 2017). Yerkürenin yüzeyinden gelen su, kabuk içindeki sıcak bölgelere ulaşmak için, bazen birkaç kilometre derinliğe kadar kaya içindeki fay ve çatlaklardan sızabildiğinde jeotermal alanlar oluşmaktadır (Breeze, 2019). Bazı bölgelerde, kabuktaki çatlaklardan akan su, sıcak kaya ile temas eder ve yüksek sıcaklıklara 1sıtılır. Bu ısıtılmış suyun bir kısmı yüzeye geri döner ve sıcak kaplıcalar-gayzerler olarak görünür (Yılmaz-İpek, 2009). Jeotermal su, derin bir yeraltı deposundan çekilen sıcak, genellikle tuzlu, mineral bakımından zengin ve yüksek sıcaklığa sahip bir akışkandır (Yavuz, 2010). Genel olarak, jeotermal akışkan kimyasal bileşenler bakımından zengindir. En önemli bileşenler; katyonlar $\left(\mathrm{Na}^{+}, \mathrm{K}^{+}, \mathrm{Ca}^{2+}, \mathrm{Mg}^{2+}, \mathrm{Li}^{+}, \mathrm{Sr}^{2+}, \mathrm{Mn}, \mathrm{Fe}\right)$, anyonlar $\left(\mathrm{Cl}^{-}, \mathrm{HCO}_{3}{ }^{-}, \mathrm{SO}_{4}{ }^{2-}, \mathrm{F}^{-}, \mathrm{Br}^{-}\right)$, iyonik olmayan türler $\left(\mathrm{Si}_{2}\right.$, $\left.\mathrm{B}, \mathrm{NH}_{3}\right)$ ve bazı spesifik türlerdir ( $\mathrm{Hg}$, As, bazı metaller). Çözünmüş yoğuşmaz gazlar arasında karbondioksit $\left(\mathrm{CO}_{2}\right)$, hidrojen sülfür $\left(\mathrm{H}_{2} \mathrm{~S}\right)$, amonyak $\left(\mathrm{NH}_{3}\right)$, azot gazı $\left(\mathrm{N}_{2}\right)$, hidrojen gazı $\left(\mathrm{H}_{2}\right)$ ve metan $\left(\mathrm{CH}_{4}\right)$ bulunmaktadir (Bertani, 2016). Jeotermal enerji kullanımının, çevreye bazı olumsuz etkileri vardır. Özellikle hava kalitesi açısından çevreye olan etkiler fazla olabilmektedir (Çakın vd., 2005). En önemlilerinden biri olan $\mathrm{CO}_{2}$, jeotermal gaz fraksiyonunun yaklaşık \%90'ını temsil etmektedir. En tehlikeli olan ve pahalı arıtım önlemleri gerektiren, toksisitesi ve ciddi çevresel etkisi nedeniyle $\mathrm{H}_{2} \mathrm{~S}$ 'tir (Bertani, 2016). Jeotermal sudaki bazı çözünmüş minerallerin aşırı konsantrasyonu (florür, demir, kalsiyum, karbonat) tortu oluşumu ve korozyon gibi çeşitli su kalitesi sorunlarına neden olmaktadır (Yavuz, 2010). Jeotermal enerjide karşılaşılan çevresel sorunlardan bir diğeri de genellikle yüzeysel ve yeraltı sularının bor, arsenik ve lityum gibi toksik ağır metaller ile kirlenmesidir (Gezmiş Yavuz, 2018). Bu nedenle jeotermal suların çevre ve ekosistem üzerinde oluşturabileceği olumsuz etkiler dikkatli bir şekilde takip edilmelidir (Er, 2016). Özellikle jeotermal santrallerden gelen atıksular yüksek sicaklığa sahiptir. Bu atıksular yüzeyde bertaraf edilirse, sığ yeraltı suyu, akarsu ve diğer yüzey suları termal olarak kirlenebilmektedir (Arnorsson vd., 2015). Bu durum, sucul ekosistemde sıcaklık değişimine son derece hassas olan bitki ve hayvan türleri için tehlikeli olabilmektedir (Er, 2016). Sonuç olarak, jeotermal akışkanların alıcı ortamlara deşarj edilmesi hem sucul ekosistem hem de bu suların çeşitli amaçlarla kullanılmasında (tarımsal sulama gibi) zararlara yol açabilmektedir. Bu nedenle, yüzeye çıkan jeotermal akışkanların, ekonomik açıdan uygun yöntemler kullanılarak yüzeysel su ortamlarından uzaklaştırılması veya en aza indirgenmesi gerekmektedir (Yavuz, 2010).

$\mathrm{Bu}$ çalışmada, jeotermal kaynakların Dünya'daki ve Türkiye'deki durumu incelenerek, jeotermal suların kimyasal bileşimi, uygulama alanları ve çevresel etkileri irdelenmiştir. Jeotermal suların çevreye olan etkilerinin azaltılması için dikkat edilmesi gereken hususlar ve alınması gereken önlemler araştırılmıştır. $\mathrm{Bu}$ çalışmanın ana amacı; jeotermal enerji/jeotermal suların kullanım alanları ve jeotermal kuyu/buharlardan gelen deşarjların oluşturduğu çevresel problemlerin detaylı olarak değerlendirilerek yenilikçi arıtma alternatiflerinin de dahil olduğu çözümlerin ortaya konmasıdır.

\subsection{Jeotermal Kaynakların Dünya'daki ve Türkiye'deki Durumu}

Dünyada, yenilenebilir enerjinin benimsenmesi, küresel enerji dönüşümü ve iklim değişikliğinin azaltılması için önemli bir strateji haline gelmiştir (Xia ve Zhang, 2019). Enerji üretimi için jeotermal kaynak kullanmanın avantajları: (1) günde 24 saat kesintisiz elektrik üretimi, (2) temiz ve sürdürülebilir enerji üretimi, (3) artan enerji güvenliği, (4) $\mathrm{CO}_{2}$ emisyonlarının ve diğer hava ve su kirleticilerin azaltılması (5) daha az tatlı su tüketimi ve (6) işletme esnekliğidir. Günümüzde jeotermal enerjinin en fazla kullanımı elektrik üretimi alanındadır (Pan vd., 2019). Amerika Birleşik Devletleri'nde 60 jeotermal enerji santrali elektrik üretmekte ve bu jeotermal enerji santrallerinin çoğu, Nevada, Hawaii, Idaho Utah ve Kaliforniya'da bulunmaktadır (Khare vd., 2019). Alp-Himalaya kuşağı, Dünyanın en büyük jeotermal kuşakları arasında olup, İtalya, Yunanistan, Macaristan, Türkiye, İran, Pakistan, Hindistan, Tibet ve Çin ülkeleri bu kuşakta yer alan ülkelerdir (Ilgar, 2005). Belirtilen bu büyük kuşaklar dışında Japonya, Filipinler, Endonezya, Yeni Zelanda, İrlanda ve Meksika oldukça zengin jeotermal kaynakları olan ülkelerdir (Kalınc1, 2006). Jeotermal enerjiden elektrik üretiminde ilk beş ülke; ABD, Filipinler, Endonezya, Türkiye ve Yeni Zelanda'dır. Elektrik dışı kullanım $70.000 \mathrm{MW}_{\mathrm{t}}{ }^{\prime} 1$ aşmış olup dünyada doğrudan kullanım uygulamalarındaki ilk 5 ülke ise ABD, Çin, İsveç, Belarus ve Norveç’tir (MTA, 2021). Dünyada jeotermal enerji kurulu gücü 2018 yılı sonu verilerine göre $14.9 \mathrm{GW}_{\mathrm{e}}$ düzeyindedir (MTA, 2021). Uluslararası Enerji Ajansı (2011) tarafindan 'Jeotermal Is1 ve Enerji Teknolojisi Yol Haritasına’ göre, jeotermal elektrik 
üretiminin 2050 yılına kadar yılda $1400 \mathrm{TW}_{\mathrm{h}}$ değerine ulaşacağı rapor edilmiştir (Pan vd., 2019). 2017 yılında, en büyük kurulu jeotermal enerji kapasitesine sahip ülkeler Amerika Birleşik Devletleri $(\sim 3,72 \mathrm{GW})$, Filipinler $(\sim 1.93 \mathrm{GW})$, Endonezya $(\sim$ $1.86 \mathrm{GW})$, Türkiye $(\sim 1.06 \mathrm{GW})$, Yeni Zelanda $(\sim 0.98 \mathrm{GW})$, Meksika ( $0.92 \mathrm{GW})$, İtalya $(\sim 0.92 \mathrm{GW})$ ve İzlanda $(\sim 0.71$ $\mathrm{GW}$ )'dır (BP, 2019). Kasım 2020 verisine göre jeotermal enerji santrali kurulu güçleri; ABD (3.700 $\mathrm{MW}_{\mathrm{e}}$ ), Endonezya (2.289 $\left.\mathrm{MW}_{\mathrm{e}}\right)$, Filipinler $\left(1.918 \mathrm{MW}_{\mathrm{e}}\right)$, Kenya $\left(1.193 \mathrm{MW}_{\mathrm{e}}\right.$ ) ve Türkiye (1.579 $\mathrm{MW}_{\mathrm{e}}$ ) öne çıkmaktadır (Huttrer, 2020). Buna göre, 2000 yılında yaklaşık $10.000 \mathrm{MW}_{\mathrm{e}}$ olan dünya toplam kurulu güç kapasitesi, 2020'de 20.000 MW' 'ye yaklaşmış ve yaklaşık iki kat artmıştır (Baba vd., 2021).

Birçok ülke kömür, petrol ve doğalgaz gibi başlıca küresel enerji kaynakları bakımından zengin değildir (Ketilsson vd., 2015). Son 25 yılda, Türkiye'nin enerji tüketimi, ekonomik büyümesine paralel olarak artmıştır (Melikoglu, 2017). Küresel olarak, son otuz yılda iki katına çıkan sera gazı emisyonları ve fosil yakıt fiyatlarının değişkenliği birçok ülkeyi yenilenebilir enerji kaynaklarına olan yatırımlarını artırmaya teşvik etmiştir (Al-Mulali vd., 2013). Buna bağlı olarak Türkiye, önümüzdeki yıllarda enerji talebinin \%30'unu yenilenebilir enerji kaynaklarından üretme hedefini belirlemiştir (Melikoglu, 2017). $\mathrm{Bu}$ durum Türkiye dahil diğer ülkeler için jeotermal enerji üretiminin gelişmesine ana etken olmuştur (Xia ve Zhang, 2019). Türkiye jeotermal kaynaklar bakımından zengin bir ülkedir (Aksoy, 2014). Isınmadan termal turizme kadar jeotermal enerji kullanımı konusunda yüksek miktarda uygulama ve kullanım sağlanmaktadır (Dincer ve Ozcan, 2018). Türkiye'deki ilk jeotermal araştırmalar ve incelemeler 1962 yılında MTA tarafından başlatılmıştır (Mertoglu vd., 2019). Ülkemizde jeotermal alanların \%78'i Batı Anadolu'da, \%9'u İç Anadolu'da, \%7 si Marmara Bölgesinde, \%5'i Doğu Anadolu'da ve \%1'i diğer bölgelerde yer almaktadır (MTA, 2021). Türkiye, jeotermal enerjiden elektrik üretimi ve doğrudan kullanım uygulamalarında (1sıtma, termal turizm, mineral çıkarma) önde gelen ülkeler arasındadır (Hepbasli ve Canakci, 2003). Türkiye'de başlıca uygulamalar kapsamında 60 kayıtli jeotermal enerji santrali ve 18 bölgesel şehir 1sınması bulunmaktadır (Enerji Atlası, 2021). Ülkemizde, özel sektörün jeotermal arama, geliştirme ve yatırım çalışmaları ile birlikte toplam jeotermal 1sı kapasitesi 35.500 $\mathrm{MW}_{\mathrm{t}}$ 'e ulaşmıştır (ETKB, 2021). MTA ve özel sektör verilerine göre Türkiye genelinde $20-287^{\circ} \mathrm{C}$ arasında değişen sıcaklıklara sahip olduğu bilinen 460 'dan fazla jeotermal alan ve 2000 'den fazla sıcak su ve maden suyu kaynağı tespit edilmiştir (Lund ve Toth, 2021). Yeni sahaların keşfiyle jeotermal alan sayısı arttırılmış olup, bugüne kadar toplam 634 adet 412.250 metre sondajlı arama çalışması yapılmıştır (MTA, 2021). Ülkemiz, Aralık 2020 sonunda jeotermal kaynaklardan elektrik üretiminde $1613 \mathrm{MW}_{\mathrm{e}}$ kurulu güce ulaşmış ve Dünyada jeotermal kaynaklardan elektrik üretiminde 4. sırada yerini almıştır. Jeotermal enerjinin toplam elektrik üretimi içerisindeki payı ise \%3,25 olarak belirlenmiştir (ETKB, 2021). Türkiye'de 2021 y1lı Şubat ayında devrede olan santrallerin \%52,1'ini yenilenebilir kaynaklardan elektrik üreten santraller oluşturmuştur. Hidroelektrik santraller, Türkiye toplam elektrik kurulu gücünün $(\% 32,2)$ 'sini, termik santraller $(\% 47,9)$, rüzgar $(\% 9,5)$, güneş $(\% 7,1)$, jeotermal $(\% 1,7)$, ve biyokütle enerjisi $(\% 1,6)$ 'sını temsil etmiştir (TSKB, 2021). Türkiye Elektrik İletim A.Ş. (TEİAŞ), 2021 Şubat Kurulu Güç Raporunda Türkiye'nin 60 adet jeotermal santral ile 1623,9 MW kurulu güce sahip olduğunu açıklamıştır (TEİAŞ, 2021). Mart 2021 itibarıyla ülkemizin elektrik üretim santralleri kurulu gücü 97.000 MW'1 geçmiş olup bunun 1.696
MW'1 jeotermal elektrik santralidir (Enerji Portalı, 2021). Enerji ve Tabii Kaynaklar Bakanlığı'nın 2019-2023 Stratejik Planına göre, 2023 yılına kadar yenilenebilir enerji kurulu kapasitelerinin hedefleri; rüzgar: $11.883 \mathrm{MW}$, hidroelektrik: $32.037 \mathrm{MW}$, jeotermal-biyokütle: $2884 \mathrm{MW}$, güneş: $10.000 \mathrm{MW}$ ve yerli kömüre dayalı elektrik kurulu gücü: $14.664 \mathrm{MW}$ olarak belirlenmiştir (ETKB, 2020). Jeotermal enerji santrali kurulu güçlerine bakıldığında, son dönemlerde hem yeni jeotermal enerji santrallerinin devreye girdiği hem de enerji santrali kurulu gücünün sürekli arttığı ifade edilebilir. Ayrıca, ülkemizin elektrik üretimi ve doğrudan kullanımlar için jeotermal kaynaklar bakımından zengin ve elverişli olduğunu görmek mümkündür.

\section{Jeotermal Enerji ve Jeotermal Suların Uygulama Alanları}

Jeotermal enerji, doğrudan kullanım ve elektrik üretimi olmak üzere iki genel şekilde kullanılmaktadır (Dincer ve Ozcan, 2018). Jeotermal kaynakların doğrudan kullanımı temel olarak 1sıtma ve soğutma içindir (Lund, 2007a). Jeotermal kaynakların 1sıtma uygulamaları için doğrudan kullanılması, elektrik üretiminden daha düşük sıcaklıklarda kaynaklar kullanılarak gerçekleştirilmektedir (DiPippo ve Renner, 2014). Elektrik üretimi teknolojileri (buharlı enerji santralleri, hidrotermal ve ikili çevrim enerji santralleri) sırasıyla yüksek, orta ve düşük entalpili üç jeotermal enerjiye dayanmaktadır (Santos vd., 2018). Yüksek sicaklıktaki jeotermal rezervuarlar $\left(150-300^{\circ} \mathrm{C}\right)$, buhar ve elektrik üretimi dahil olmak üzere dolaylı kullanım uygulamaları için kullanılmaktadır (Van Nguyen vd., 2015). Dünyada jeotermal kaynakların doğrudan kullanımındaki oranlar (elektrik dışı); jeotermal konut 1sıtması \%74,8, kaplıca-sağlık amaçlı kullanım $\% 18$, sera 1 sitması $\% 3,5$, jeotermal balıkçılık $\% 1,3$, endüstriyel kullanım \%1,6, soğutma-kar eritme $\% 0,2$ ve diğer $\% 0,2$ 'dir (TJD, 2021). Jeotermal kaynakların en eski kullanımı iyileştirici özellikleriyle bilinen kaplıcalardır (IGA, 2018). Türkiye, doğrudan kullanım bakımından şifalı jeotermal sular ve kaplıcalar bakımından da Avrupa'nın önde gelen ülkesidir (Özbek, 2011). Türkiye'nin jeotermal suyunun balneolojik kullanımından 20 milyon yerli ve yaklaşık 20.000 yabancı ziyaretçi faydalanmaktadır (Lund ve Toth, 2021).

Elektrik üretme ve yüksek kalitedeki hidrotermal sistemlerden bölgesel 1sıtma/dağıtma için jeotermal 1S1 pompası teknolojileri oldukça gelişmektedir (Sowizdzal, 2018). Jeotermal kaynakların doğrudan kullanımındaki en hızlı artış, jeotermal veya toprak kaynaklı 1sı pompası teknolojisindedir (DiPippo ve Renner, 2014). Bir 1sı pompası, kışın ısıyı evin içine pompalar ve yaz aylarında evin içinden tekrar dişarı isı pompalar (Towler, 2014). Jeotermal bölgesel 1sıtma uygulamalarına Çin öncülük etmekte, ardından İzlanda ve Türkiye gelmektedir (Lund ve Boyd, 2016). İzlanda, yerden 1sitma ihtiyacının \%89'u jeotermal enerjiden karşılanmaktadır (Lund, 2007a). ABD'de jeotermal kaynak suları uzun süredir evleri ve binaları 1sıtmak için kullanılmaktadır. İzlanda'da, hemen hemen tüm ülkede her bina jeotermal akışkanlar ile isıtılmaktadır (Towler, 2014). Türkiye'de jeotermal enerjinin ilk yerden 1sıtma uygulaması 1964'te GönenBalıkesir'de bir otelde gerçekleştirilmiştir. İlk bölgesel 1sıtma sistemi 1987'de 16,2 MWt kapasiteli yine Gönen'de inşa edilmiştir (Gulden vd., 2003). 450 jeotermal kaplıca dahil 46.400 konut eşdeğerinde kaplıcalara, otellere ve devre mülk tesislerine 1sıtma sağlanmaktadır. Bugün ülkede toplam 90 adet kapalı devre jeotermal 1s1 pompası sistemi bulunmaktadır (Lund ve Toth, 2021). 
Tarımsal ve tarımsal-endüstriyel kullanımlar jeotermal enerji uygulamalarının çok önemli bir bölümünü oluşturmaktadır. Genel olarak, tarımda dört tür doğrudan jeotermal enerji uygulaması görülmektedir: sera 1sıtmas1, tarımsal sanayi, toprak 1sıtmas1, su ürünleri yetiştiriciliği (balık yetiştiriciliği ve alg üretimi) (Popovski, 2009). Jeotermal 1sı, seralarda tarımsal ürünlerin en iyi şekilde büyümeleri için optimum sıcaklığın sağlanması amacıyla kullanılmaktadır (Soelaiman, 2016). Sebzeler, çiçekler ve meyveler bu seralarda yetişen başlıca ürünlerdir. Seraların 1sıtılması için gerekli jeotermal su sıcaklığı, sera içinde gerekli sıcaklığa bağlı olarak 40 ile $100^{\circ} \mathrm{C}$ arasındadır (Popovski ve Vasilevska, 2003). Su, bitkiler arasında, toprağın altına veya üstüne yerleştirilmiş bakır veya çelik borulardan geçmektedir (Panagiotou, 1996). Borular içerisinde dolaşan sudan gelen 1s1 seradaki toprağa ve havaya aktarılır (Van Nguyen vd., 2015). Türkiye'de jeotermal sera 1sıtma uygulamaları son beş yılda 4,3 milyon $\mathrm{m}^{2}$ ye ulaşmıştır (Mertoglu vd., 2019). Jeotermal ısıtmalı seraların çoğunluğu Ege bölgesindedir (Gunerhan vd., 2001). Toprak 1sıtma, büyüme mevsiminin uzatılmasını ve verimi artırmak için sabit bir toprak sıcaklığının korunmasının mümkün olmasını sağlamaktadır. Seralardan gelen atıksular da bazen toprağı 1sıtmak için kullanılabilmektedir (Kumoro ve Kristanto, 2003). Jeotermal enerji; pirinç, buğday, domates, soğan, pamuk, biber ve sarımsak gibi çok çeşitli tarımsal ürünleri kurutmak için kullanılmıştır (Van Nguyen vd., 2015). Kurutma 1sısı, jeotermal kuyuların sicak suyundan veya buharından veya bir jeotermal tesisten atık 1S1 geri kazanılarak elde edilebilir (Vasquez vd., 1992). Son olarak jeotermal sıcak su, 1sı dönüştürücülerde tatlı suyu 1sıtmak için kullanılmakta veya balık yetiştiriciliği için uygun sıcaklıkları elde etmede tatlı su ile karıştırılmaktadır (Van Nguyen vd., 2015). Balık yetiştiriciliğinde jeotermal enerjinin kullanılması, balık stoklarını soğuk havaya karşı korur, suyu optimum sıcaklığa getirir ve balık üretimini arttırır (Gelegenis vd., 2006). İzlanda'da jeotermal su kullanan yaklaşık 70 balık çiftliği vardır. Ayrıca İzlanda, \%70'e karşılık gelen jeotermal kar eritme uygulamalarıyla da dünyaya liderlik etmektedir (Dincer ve Ozcan, 2018).

\subsection{Jeotermal Enerji ve Jeotermal Suların Çevresel Etkileri}

Jeotermal enerji, fosil yakıtlarla kıyaslandığında temiz bir enerji kaynağı olarak kabul edilebilmektedir. Bununla birlikte, jeotermal kaynakların kullanımının çevresel etkisi de oldukça önemlidir (Arnorsson vd., 2015). Jeotermal enerjiden kaynaklı doğrudan çevresel etkiler, atmosferik emisyonlardan, arazi kullanımından, katı atıklardan, su tüketiminden ve sahaya bağlı olarak biyolojik çeşitliliğe yönelik belirli tehditlerden kaynaklanmaktadır. Dolaylı çevresel etkiler ise, santral inşaatı gibi ilgili proje faaliyetlerinden kaynaklanmaktadır (Bayer vd., 2013). Büyük ölçekli üretim, sondaj çalışmaları ve bakım, peyzaj üzerinde görsel etkiler oluşturabilmektedir. Aynı zamanda gürültü kirliliği ve atık oluşturarak hem çevreyi hem de ekonomiyi etkileyebilmektedir (Khare vd., 2019). Kisaca jeotermal enerji kullanımının genel olumsuz etkileri arasında; hava kirliliği (zararlı gaz emisyonları), su kirliği, gürültü kirliliği, arazi kullanımı, katı atıklar, termal kirlilik, toprak çökmesi, doğal manzaraların değişmesi, sismik aktivitenin başlatılması/arttırılması, yaban hayatı ve bitki örtüsü üzerindeki etkiler sayılabilmektedir (DiPippo, 2016).

Jeotermal enerji kullanımının genel olarak en fazla endişe verici olan çevresel etkisi, hava ve su kaynaklı kirleticilerden oluşan kimyasal kirliliktir (Arnorsson vd., 2015). Jeotermal enerji santralleri, fosil yakıt kullanan santrallere kıyasla daha az $\mathrm{CO}_{2}$ emisyonuna sahiptir (DiPippo, 2016). Bunun yanı sıra uçucu organik maddeler/metaller jeotermal tesislerden yayllabilmektedir (Pan vd., 2019). Jeotermal buhar veya sicak su genellikle, $\mathrm{CO}_{2}, \mathrm{H}_{2} \mathrm{~S}, \mathrm{NH}_{3}, \mathrm{CH}_{4}$ ve az miktarda diğer gazları içermektedir. Ayrıca buhar, az miktarda cıva ( $\mathrm{Hg})$, bor (B) ve radon ( $\mathrm{Rn}$ ) gibi elementleri de içerebilmektedir. Bor, amonyak ve daha az miktarda cıva, yağışlar yolu ile toprak ve bitki örtüsü kirlenmesine neden olmaktadır (Barbier, 2002). Yoğuşmaz gazların büyük çoğunluğu (\%95-99) $\mathrm{CO}_{2}$ iken geri kalanı $\mathrm{H}_{2} \mathrm{~S}$ ve $\mathrm{CH}_{4}$ 'tür (Aksoy, 2014). Jeotermal buharda genellikle çevresel açıdan en büyük endişe kaynağı olan gaz $\mathrm{H}_{2} \mathrm{~S}$ 'tir. $\mathrm{Bu}$ gaz oldukça zehirli, aşındırıcı ve zararlı bir kokusu vardır (Arnorsson vd., 2015). $\mathrm{H}_{2} \mathrm{~S}$ emisyonlarının, belirli konsantrasyonlarda insanlar ve bitkiler üzerindeki zararlı etkileri olmaktadır (DiPippo, 1991). Jeotermal çalışmalar (arama, üretim aşamaları vb.) sırasında ortaya çıkan sıvı akımlarda bulunan çözünmüş mineraller yüzey veya yeraltı sularının kalitesini bozabilmektedir (Tester vd., 2006). Bu akışkanlar; insanlara, bitki örtüsüne veya faunaya zararlı mineraller ve elementler içermektedir (DiPippo, 2016). Bu nedenle, kuyu açma ve sonraki işlemler sırasında kuyuların izlenmesi oldukça önemlidir (Van Nguyen vd., 2015). Bir jeotermal enerji projesinin geliştirme aşamasında, yol yapımı, sondaj sahaları için kazı, kuyu delme ve kuyu testleri sırasında gürültü oluşmaktadır (DiPippo, 2016). Bir santralin gürültüsü, tesisin yanında veya içinde olunmadığı sürece, çok düşük olduğu için endişe konusu olarak kabul edilmemektedir (Lund, 2007a).

Jeotermal rezervuarların üstündeki jeolojik oluşum yetersiz ise, rezervuardaki su seviyesinin düşürülmesi sıvının gözenek alanlarından boşalmasına neden olmaktadır. Bu durum çökmeyle beraber arazinin de çöküşüne neden olmaktadırlar (Arnorsson vd., 2015). Buna en iyi örnek, jeotermal akışkanın 50 yıl boyunca çıkarılması nedeniyle $15 \mathrm{~m}$ arazi çökmesi olan Wairakei jeotermal alanıdır (Allis vd., 2009). Çökme, kullanılan akışkanların yeniden enjeksiyonuyla kontrol edilebilmekte veya önlenebilmektedir (Barbier, 2002). 2017 yılında Güney Kore'de bulunan Pohang jeotermal alanında meydana gelen deprem insanların yaralanmasına yol açmıştır (Kim vd., 2018). Birçok jeotermal alan, doğal toprak kaymalarına eğilimli engebeli volkanik arazide bulunmaktadır (DiPippo, 2016). Santraller, buhar besleme sistemleri ve buhar boru hatlarının geçtiği alanlar özellikle engebeli arazide arazi yüzeyini bozmaktadır. Yağışlarla birlikte, toprak kaymalarına ve yüksek toprak erozyon oranlarına neden olabilmektedir (Arnorsson vd., 2015). Bir jeotermal tesiste meydana gelebilecek diğer ciddi olaylar arasında kuyu patlamaları, yeraltı suyu patlamaları, yırtılmış buhar boruları, türbin arızaları, yangınlar vb. bulunmaktadır (DiPippo, 2016). Jeotermal enerji gelişimi, özellikle enerji santralleri ve iletim hatlarının inşası tarımsal kaynaklar üzerinde etki oluşturabilmektedir. İnşaat faaliyetleri, vahşi yaşamı tahrip ettiğinde, üreme, göç durumlarını bozduğunda, habitat kalitesini ve tür çeşitliliğini azalttığında ekolojik kaynaklar üzerinde etkileri vardır (Van Nguyen vd., 2015). Jeotermal enerji santrali için düşünülen herhangi bir alan, yaban hayatı ve bitki örtüsü üzerindeki etki için incelenmeli ve bir azaltma planı sağlamalıdır (Lund, 2007b). Jeotermal santrallerde üretilen katı atı miktarı düşük olduğu için önemli bir çevresel sorun oluşturmamaktadır (DiPippo, 2012). Bu tesislerdeki katı atık, esas olarak sondaj çamuru ve sondaj açma sırasında üretilir. Diğer kirleticiler ise ambalaj atıkları, kauçuk atıkları, filtreler, kentsel atıklar ve bazı metaller gibi çeşitli atıklardır. Jeotermal santral ekipmanlarının doğru kurulumu, periyodik kontrolü, toprak ve su izleme çalışmalarının tam zamanlı yapılması, katı atık/tehlikeli atık 
ayırma ve depolama ile atık oluşumu azaltılabilmektedir (Soltani vd., 2021).

Orta ve yüksek sıcaklıktaki jeotermal sistemler için jeotermal enerji santrallerinin çalışmasında tortulaşma ve korozyon sorunları gözlemlenebilmektedir. Korozyon ve tortu problemleri enerji üretiminde ciddi zorluklar yaratmakta ve jeotermal yatırımcının toplam işletme maliyetini artırabilmektedir (Kaya ve Hoşhan, 2005). Tortu ve korozyon, doğrudan jeotermal akışkanın özellikleri ile ilgilidir (Finster vd., 2015). Tortulaşma, jeotermal sulardaki bazı minerallerin, basınç ve sıcaklık gibi termodinamik koşullardaki değişimin eşlik ettiği bir çökelmedir (Tut Haklidir ve Haklidir, 2017). Basınç, sıcaklık veya kaya kimyasının aniden değiştiği yerlerde, minerallerin çökmesi tesisat sisteminin tıkanmasına neden olmaktadır (GC, 2019). Sulu çözeltilerde gözlemlenen tortulaşma birikimleri: kalsiyum karbonat (kalsit), kalsiyum sülfat, kalsiyum oksalat, baryum sülfat (barit), magnezyum hidroksit, silikatlar (serpantin, amorf silika, kuvars), alüminosilikatlar, alüminyum oksit hidroksitleri, bakır ve fosfattır (Hoang, 2015). Silika $\left(\mathrm{SiO}_{2}\right)$, jeotermal rezervuarlarda rastlanılan temel bileşendir (Van den Heuvel vd., 2018). Silika minerali gerek jeokimyası gerek çözünürlüğü bağlamında en zorlu tortu türlerinden biridir (Tut Haklidir ve Haklidir, 2017). Silika tortulaşması, boru hatlarında jeotermal akışkanın hidrolik akış kapasitesini düşürür (Pambudi vd., 2015). Silisli tortu birikimini kontrol etmek için jeotermal tuzlu su ve soğutma sularında organik tortu önleyiciler, tortulaşmayı ve korozyonu azaltmak için kullanılmaktadır (Gallup ve Hirtz, 2015). Korozyon ise, jeotermal akışkan ve proses ekipmanının iç yüzeyleri arasındaki kimyasal etkileşimlerden kaynaklanmaktadır (Finster vd., 2015). Sicak jeotermal tuzlu sular son derece koroziftir. Bu nedenle metalik malzemelerinin korozyonu jeotermal endüstrisindeki operatörler için endişe kaynağıdır (Mundhenk vd., 2013). Korozyon genellikle, yüksek sıcaklığa sahip ve kullanılmış tuzlu suda aşındırıcı türlerin varlığından kaynaklanmaktadır. Bu ana türler şunlardır: oksijen, hidrojen iyonu konsantrasyonu (veya $\mathrm{pH}$ ), klorür iyonu, hidrojen sülfür $\left(\mathrm{H}_{2} \mathrm{~S}\right)$, karbon dioksit $\left(\mathrm{CO}_{2}\right)$, karbonat $\left(\mathrm{CO}_{3}{ }^{2-}\right)$ ve bikarbonat $\left(\mathrm{HCO}_{3}{ }^{-}\right)$iyonları, amonyak $\left(\mathrm{NH}_{3}\right)$, amonyum iyonu $\left(\mathrm{NH}_{4}{ }^{+}\right)$ve sülfat $\left(\mathrm{SO}_{4}{ }^{2-}\right)$ iyonu (Nogara ve Zarrouk, 2018). Korozyon genellikle, tesis tasarım sürecinde korozyona dayanıklı malzemelerin kullanılması ile yönetilebilmektedir (Clark vd., 2010).

Jeotermal akışkanlar; jeotermal enerji arama, saha geliştirme ve elektrik santrali işlemlerinin çeşitli aşamalarında yerinde üretilen sıvı çeşitlerini kapsamaktadır. Genel olarak, jeotermal tesislerde üretilen sular bir kuyudan çıkan ve kullanılan akışkanı içermektedir (Finster vd., 2015). Yüksek sıcaklıktaki jeotermal sistemlerde, sıv1-kaya etkileşiminin daha uzun olması nedeniyle, jeotermal sular büyük miktarda kimyasal türü çözebilmektedir (Cao vd., 2017). Jeotermal rezervuardan yüksek sıcaklıkta ve genellikle yüksek basınç altında çıkan sıvı; silika, borik asit ve metalik tuzlar gibi çok yüksek miktarda çözünmüş mineral içermektedir. Hidrojen sülfür ve karbondioksitte sıklıkla bulunmaktadır (Breeze, 2019). Yüksek sicaklıktaki jeotermal suların çoğu, alüminyum, bor, arsenik, kadmiyum, kurşun, cıva ve bazen florür gibi toksik kimyasallardan en az birinin yüksek konsantrasyonlarını içerebilmektedir (GC, 2019). Suyun hâkim olduğu jeotermal sistemlerde, derinliklerde bulunan en yaygın birincil akışkan tipi, başta $\mathrm{CO}_{2}$ olmak üzere gaz içeren sodyumklorür tuzlu sularıdır (Barbier, 2002). Jeotermal suların pH değerleri ortalama 7.3 civarında olup, 5-10 arasında değişkenlik göstermektedir (Finster vd., 2015).
Bir jeotermal projenin geliştirilmesinin her aşamasında suya ihtiyaç vardır. Çoğu durumda çevresel etkileri en aza indirmek için su kullanımı yönetilebilmektedir. Su kullanımının iki ana alanı, kuyu sondajı ve su soğutma kulesi kullanılıyorsa atık ısının boşaltılmasıdır (DiPippo, 2016). Tesislerdeki su soğutma kuleleri, suyun \%50'den fazlasını tüketmektedir (Clark vd., 2010). Nehirlerin ve göllerin su kirliliği, enerji üretiminde ve kullanılan jeotermal akışkanların yönetiminde potansiyel bir tehlike oluşturmaktadır (Barbier,2002). Jeotermal santrallerden gelen atıksular, deşarj ortamlarından daha yüksek bir sıcaklığa sahiptir. $\mathrm{Bu}$ sular, nehirler, göller ve deniz ekosistemini korumak için depolama havuzlarında veya tanklarda soğutulabilmektedir (Dickson ve Fanelli, 2004). Atıksu yüzeyde bertaraf edilirse, sı̆̆ yeraltı suları, akarsu ve diğer yüzey suları termal olarak kirlenebilmektedir (Arnorsson vd., 2015). Ayrica santralden gelen buhar akışı da (buhar ejektörleri, soğutma kuleleri), hem görsel hem de termal kirlenmelere yol açmaktadır. Bir jeotermal sondaj deliğinden gelen konsantre tuzlu su genellikle aşındırıcıdır ve yerel yeraltı suyu kaynaklarının kirlenmesine neden olabilir (Breeze, 2019). Jeotermal akışkan deşarjlarının bileşimleri Li, B, As, $\mathrm{NH}_{3}, \mathrm{Hg}, \mathrm{Cl}$ ve $\mathrm{H}_{2} \mathrm{~S}$ içerebilmektedir. $\mathrm{Bu}$ maddeler sucul yaşam, sulama suyu, yüzeysel sular ve insanlar için içme suyu üzerinde toksik çevresel etkileri olabilmektedir (Purnomo ve Pichler, 2014). Jeotermal atıksuyun, bir kullanım tesisinden deşarjı sonucu bir su kütlesinin sıcaklığındaki sadece $2-3^{\circ} \mathrm{C}^{\prime}$ lik bir artış su ekosistemine ciddi zararlar verebilir. Su sıcaklığındaki artış, balık türlerinin yumurtalarının gelişimini de engelleyebilmektedir (Dickson ve Fanelli, 2004). Sonuç olarak, jeotermal enerji tesislerinden gelen tüm deşarj sıvılarını toplamak ve yeniden enjeksiyon yoluyla enjekte etmek iyi bir uygulamadır (DiPippo, 1991). Jeotermal enerji kullanımının ilk yıllarında, atıksu genellikle mevcut en ucuz yöntemlerle bertaraf edilmiştir. $\mathrm{Bu}$ yöntemler, en yakın akarsuya ya da bu amaç için inşa edilmiş göletler içine yüzeysel deşarj şeklindedir (Arnorsson vd., 2015). Jeotermal tesislerde çevre üzerindeki diğer bir etki ise sondaj arama ve keşif/üretim kuyusu açma çalışmaları sırasında meydana gelen patlamalardır. Patlamalar yüzey suyunu kirletebilir. $\mathrm{Bu}$ nedenle yüksek sıcaklıkların ve basınçların beklendiği jeotermal kuyuları açarken patlama önleyiciler kurulmalıdır (Lienau ve Lunis, 1991). Kuyu açma veya akış işlemleri sırasında, istenmeyen gazlar atmosfere salınabilmektedir (Dickson ve Fanelli, 2004). Son olarak, tesislerin işletimi sırasında üretilen tüm akışkanların yeniden enjekte edilmesi durumunda, yüzey kirliliği önemli bir zorluk olarak kabul edilmeyebilir (Pan vd., 2019).

\section{Sonuç ve Tartışma}

Jeotermal enerji; magma tarafından isıtılan, çevresindeki normal yeraltı ve yerüstü sularına göre daha fazla çözünmüş mineraller ve gazlar içeren sıcak su ve buharın taşıdığı 1sı enerjisi olarak tanımlanabilmektedir. Jeotermal akışkanı oluşturan sular, yeraltındaki haznelerde sürekli beslenmekte ve kaynak yenilenebilmektedir. Yüzeyden sızan sular, kırık ve çatlaklardan yer kabuğunun derinliklerine inerek isınmaktadırlar. Daha sonra tekrar sıcak olarak yeryüzüne çıkmaktadırlar. $\mathrm{Bu}$ nedenle, beslenmenin üzerinde kullanım olmadıkça jeotermal kaynakların tükenmesi söz konusu değildir. Jeotermal kaynağın yenilenebilir, sürdürülebilir, temiz ve ucuz olması ülkeleri jeotermal kaynak kullanımına yönlendirmiştir. $\mathrm{Bu}$ nedenle jeotermal kaynaklar, ülkeler için önemli bir enerji kaynağı konumuna gelmeye başlamıştır. Jeotermal kaynaklar yaygın kullanım alanına sahiptir. Ülkemizde elde edilen jeotermal enerjiden elektrik üretimi, 1sitma (sera ve konut), termal ve sağlı turizmi, endüstriyel mineral 
eldesi ve kurutmacılık gibi alanlarda yararlanılmaktadır. Bununla birlikte, jeotermal kaynak kullanımının çeşitli zararlı etkileri de mevcuttur. Jeotermal kaynaklar beraberinde çıkardığı kükürt oksitler $\left(\mathrm{SO}_{\mathrm{x}}\right)$ nedeniyle asit yağışları oluşturabilmektedir. Jeotermal buharda bulunan $\mathrm{CO}_{2}$ 'nin hava kirliliğine yol açtığı görülmektedir. Jeotermal kaynaklar, toksik etkisi olduğu bilinen $\mathrm{H}_{2} \mathrm{~S}$ gazını da içermektedir. $\mathrm{Bu}$ gaz özellikle koku kirliliği oluşturmaktadır. Jeotermal sular, magmatik kökenli ve derinlikteki kayaçları aşındırarak, bünyesine bu kayaçların mineral ve tuzluluk özelliklerini almaktadırlar. Yeryüzüne çıktıklarında ise, yüzeysel akış sularıyla karışarak bu suların fiziksel, kimyasal, biyolojik yapılarını bozmaktadırlar. Ayrıca, yüksek sıcaklık içeren jeotermal kaynak suları, hem hayvanların hem de bitkilerin zarar görmesine neden olmaktadır. Yeraltından büyük miktarda su çekilmesi ile rezervuar gözenekleri boşalmakta ve bunun sonucunda çökmeler görülebilmektedir. Bunun yanı sıra, sondajlı çalışmalar sonucu üretilen akışkanlarda çeşitli kimyasal kirleticilerle karşılaşılmaktadır (bor, arsenik, lityum vb). Ancak bu sorun, uygun ortam şartlarında tekrar enjeksiyon yapılarak aşılmaya çalışılmaktadır. Jeotermal akışkanların sondaj kuyularında ve tesisatta akışı sırasında tortulaşma ve korozyon problemleriyle de karşılaşılmaktadır. $\mathrm{Bu}$ durumlar, rezervuar basıncının yüksek tutulması veya korozyon önleyici inhibitörlerin kullanımı ile engel olunmaktadır.

Jeotermal akışkanların, nehir veya akarsuya deşarj edilmesi durumunda yüzeysel su kirliliği oluşmaktadır. Jeotermal kirleticiler, sucul ekosistem ve karasal ortamı etkilemektedir. Ayrıca bu kirleticiler, yüzeysel sulara karışarak su kimyasını büyük ölçüde değiştirebilmektedir. Jeotermal atıksular ciddi miktarlarda bor içermektedir. Aynı zamanda, lityum, arsenik, cıva, hidrojen sülfür ve amonyak gibi çeşitli kirleticileri de bulundurabilmektedirler. Günümüzde, jeotermal atıksuyun uzaklaştırılması için en çok kullanılan yöntem kullanılan suyun yeraltına yeniden enjekte edilmesidir. Tekrar enjeksiyon işlemi ile hem kirlilik problemleri elimine edilmekte hem de sicak suyun tekrar rezervuara beslenmesi sağlanarak ısı ve hidrolik kayıplar azaltılmaktadır. Fakat bu durum pratikte birçok jeotermal sahada uygulanamamakla birlikte kirlilik ve doğal afet sorunlarını da beraberinde getirmektedir. Bu sorunlar hatalı tekrar enjeksiyon sonucunda yeraltı suyu kirliliği ve mikro depremler olarak bilinmektedir. Ek olarak, giderek artan kullanım nedeniyle çeşitli bertaraf yöntemlerinin araştırılması gerekmektedir. Bu bağlamda, çeşitli kirleticiler içeren jeotermal suların verimli ve ekonomik arıtma yöntemleriyle arıtılması gerekmektedir. En çok kullanılan arıtma yöntemleri; iyon değişimi, adsorpsiyon, elektrokoagülasyon, ultrafiltrasyon, nanofiltrasyon, ters osmoz ve çeşitli hibrit proseslerdir. Bu arıtma teknikleri ile jeotermal suların içerdiği çeşitli kirleticiler uzaklaştırılarak sulama ve benzeri amaçlı kullanımı sağlanabilmektedir.

\section{Teșekkür}

Yazar Saadet ACAR, 100/2000 Yükseköğretim Kurulu (YÖK) doktora programı kapsamında "Sürdürülebilir Su Kaynakları" tematik alanında doktora bursiyeridir.

\section{Kaynakça}

Aksoy, N. (2014). Power generation from geothermal resources in Turkey. Renewable Energy, 68, 595-601.

Allis, R., Bromley, C., \& Currie, S. (2009). Update on subsidence at the Wairakei-Tauhara geothermal system, New Zealand. Geothermics, 38(1), 169-180.
Al-Mulali, U., Fereidouni, H. G., Lee, J. Y., \& Sab, C. N. B. C. (2013). Examining the bi-directional long run relationship between renewable energy consumption and GDP growth. Renewable and Sustainable Energy Reviews, 22, 209-222.

Anderson, A., \& Rezaie, B. (2019). Geothermal technology: Trends and potential role in a sustainable future. Applied Energy, 248, 18-34.

Arnorsson, S., Thorhallsson, S., \& Stefansson, A. (2015). Chapter 71-Utilization of Geothermal Resources. The Encyclopedia of Volcanoes (Second Edition), pp. 1235-1252.

Aydıngöz, M. (2005). Afyonkarahisar Bölgesinde Bulunan Kaplica Sularının Mevsimsel Analizi. Afyonkarahisar Kocatepe Üniversitesi, Fen Bilimleri Enstitüsü, Yüksek Lisans Tezi, 93s, Afyonkarahisar.

Baba, A., Uzelli, T., \& Sozbilir, H. (2021). Distribution of geothermal arsenic in relation to geothermal play types: A global review and case study from the Anatolian plate (Turkey). Journal of Hazardous Materials, 125510.

Barbier, E. (2002). Geothermal energy technology and current status: an overview. Renewable and sustainable energy reviews, 6(1-2), 3-65.

Bayer, P., Rybach, L., Blum, P., \& Brauchler, R. (2013). Review on life cycle environmental effects of geothermal power generation. Renewable and Sustainable Energy Reviews, 26, 446-463.

Bertani, R. (2016). Deep geothermal energy for heating and cooling. In Renewable Heating and Cooling (pp. 67-88). Woodhead Publishing.

Breeze, P. (2019). Chapter 12-Geothermal Power. Power Generation Technologies (Third Edition), pp. 275-291.

British Petroleum (BP), 2019. BP Statistical Review of World Energy. p. 9, London, UK.

Cao, Y., Guo, Q., Zhuang, Y., Yu, Z., Guo, W., Zhang, C., ... \& Ren, T. (2017). Removal of harmful constituents from geothermal water by selected anion clays. Procedia Earth and Planetary Science, 17, 161-164.

Clark, C. E., Harto, C. B., Sullivan, J. L., \& Wang, M. Q. (2010). Water use in the development and operation of geothermal power plants (No. ANL/EVS/R-10/5). Argonne National Lab.(ANL), Argonne, IL (United States).

Çakın, A., Gökçen, G., \& Eroğlu, A. (2005). Jeotermal Uygulamaların Çevresel Etkileri: Balçova Jeotermal Bölgesel Isıtma Sistemi Örneği.

Dickson, M. H., \& Fanelli, M. (2004). What is geothermal energy? International geothermal association. http://users.metu.edu.tr/mahmut/pete450/Dickson.pdf Erişim tarihi: 07.10.2019.

Dincer, I., \& Ozcan, H. (2018). Geothermal Energy. Comprehensive Energy Systems, vol. 1, pp. 702-732.

DiPippo, R. (1991). Geothermal energy electricity generation and environmental impact. Energy Policy, 19(8), 798-807.

DiPippo, R. (2012). Geothermal power plants: principles, applications, case studies and environmental impact. Butterworth-Heinemann.

DiPippo, R. (2016). Chapter 23-Environmental Impact of Geothermal Power Plants. Geothermal Power Plants (Fourth Edition), pp. 657-684.

DiPippo, R., Renner, J. L. (2014). Geothermal energy. In Future Energy (pp. 471-492). Elsevier.

Enerji Atlas1, (2021). Jeotermal Enerji Santralleri. https://www.enerjiatlasi.com/jeotermal/ Son Erişim Tarihi: 03.04.2021. 
Enerji Portalı, (2021). Dünyada ve Ülkemizde Yenilenebilir Enerjinin Geleceği. https://www.enerjiportali.com/dunyadave-ulkemizde-gelecek-yenilenebilir-enerjinin/ Son Erişim Tarihi: 05.04.2021.

Enerji ve Tabii Kaynaklar Bakanlığı (ETKB), 2021. Yenilenebilir Enerji, Kaynaklar, Jeotermal. https://enerji.gov.tr/eigmyenilenebilir-enerji-kaynaklar-jeotermal Son Erişim Tarihi: 04.04.2021.

Er, S. (2016). Aydın-Buharkent Yöresindeki Jeotermal Sularında Bazı Kirletici Parametrelerin Araştırılması. Adnan Menderes Üniversitesi, Fen Bilimleri Enstitüsü, Yüksek Lisans Tezi, 129 s, Aydın.

ETKB, (2020). 2019-2023 Stratejik Plan1. https://enerji.mmo.org.tr/wpcontent/uploads/2020/05/ETKB-20192023_Stratejik_Plan\%C4\%B1.pdf Son Erişim Tarihi: 05.04.2021.

Finster, M., Clark, C., Schroeder, J., \& Martino, L. (2015). Geothermal produced fluids: Characteristics, treatment technologies, and management options. Renewable and Sustainable Energy Reviews, 50, 952-966.

Gallup, D. L., \& Von Hirtz, P. (2015). Control of silica-based scales in cooling and geothermal systems. In Mineral Scales and Deposits (pp. 573-582). Elsevier.

Gelegenis, J., Dalabakis, P., \& Ilias, A. (2006). Heating of a fish wintering pond using low-temperature geothermal fluids, Porto Lagos, Greece. Geothermics, 35(1), 87-103.

Geothermal Communities (GC), 2019. Geothermal Systems and Technologie-Chemistry of Thermal Fluids. pp. 36-47, https://geothermalcommunities.eu/assets/elearning/3.2.Corro sion\&Scalling.pdf Available: 21.10.2019.

Gezmiş Yavuz, E. (2018). Hava Boşluklu/Vakum Membran Distilasyonu Prosesleri Kullanılarak Jeotermal Sulardan Bor Giderimi. İstanbul Teknik Üniversitesi, Fen Bilimleri Enstitüsü, Yüksek Lisans Tezi, 64s, İstanbul.

Gokcen, G., Kocar, G., \& Hepbasli, A. (2003). Year-end geothermal development status of Turkey, 2002. Proceedings of IGC2003, "Multiple Integrated Uses of Geothermal Resources”, Iceland S, 10, 9-13.

Gunerhan, G.G., Kocar, G., \& Hepbasli, A. (2001). Geothermal Energy Utilization in Turkey. International Journal of Energy Research, 25(9), 769-784.

Haklidir, F. T., \& Haklidir, M. (2017). Fuzzy control of calcium carbonate and silica scales in geothermal systems. Geothermics, 70, 230-238.

Hepbasli, A., \& Canakci, C. (2003). Geothermal district heating applications in Turkey: a case study of Izmir-Balcova. Energy Conversion and Management, 44(8), 1285-1301.

Hepbasli, A., \& Ozgener, L. (2004). Development of geothermal energy utilization in Turkey: a review. Renewable and Sustainable Energy Reviews, 8(5), 433-460.

Hoang, T. A. (2015). Mechanisms of scale formation and inhibition. In Mineral Scales and Deposits (pp. 47-83). Elsevier.

Hondo, H., \& Moriizumi, Y. (2017). Employment creation potential of renewable power generation technologies: A life cycle approach. Renewable and Sustainable Energy Reviews, 79, 128-136.

Huttrer, G. W. (2020, April). Geothermal power generation in the world 2015-2020 update report. In Proceedings World Geothermal Congress (Vol. 2020, p. 17).
Ilgar, R. (2005). Ekolojik Bakışla Jeotermal Kaynaklarda Dualist Yaklaşım. Elektronik Sosyal Bilimler Dergisi (elektronik), 4 (13), 88-98.

International Geothermal Association (IGA), 2018. Geothermal Quick Guide, International Geothermal Association Inc. pp. 1-9. https://www.geothermal-energy.org/explore/what-isgeothermal/ Erişim tarihi: 28.09.2019.

Kalıncı, Y. (2006). Dikili'de Jeotermal Bölgesel Isıtma Sisteminin Araştırılması. Dokuz Eylül Üniversitesi, Fen Bilimleri Enstitüsü, Yüksek Lisans Tezi, 98s, İzmir.

Kaya, T., \& Hoshan, P. (2005, April). Corrosion and material selection for geothermal systems. In Proceedings World Geothermal Congress (Vol. 2005, pp. 24-29).

Ketilsson, J., Petursdottir, H. T., Thoroddsen, S., Oddsdottir, A. L., Bragadottir, E. R., Guðmundsdóttir, M., \& Johannesson, G. A. (2015). Legal framework and national policy for geothermal development in Iceland. In Proceedings of the 2015 World Geothermal Congress (WGC, 2015).

Khare, V., Khare, C., Nema, S., \& Baredar, P. (2019). Chapter 1Introduction to Energy Sources. Tidal Energy Systems, pp. 139.

Kim, K. H., Ree, J. H., Kim, Y., Kim, S., Kang, S. Y., \& Seo, W. (2018). Assessing whether the $2017 \mathrm{Mw} 5.4$ Pohang earthquake in South Korea was an induced event. Science, 360(6392), 1007-1009.

Koç, E., \& Şenel, M. C. (2013). Dünyada ve Türkiye'de enerji durumu-genel değerlendirme. Mühendis ve Makina, 54(639), $32-44$.

Kumoro, A. C., \& Kristanto, D. (2003). Preliminary study on the utilization of geothermal energy for drying of agricultural product.

Külekçi, Ö.C. (2010). Yenilenebilir Enerji Kaynakları Arasında Jeotermal Enerjinin Yeri ve Türkiye Açısından Önemi. Ankara Üniversitesi, Ziraat Fakültesi Peyzaj Mimarlığı Bölümü, sf. 83-91, Ankara.

Li, K., Bian, H., Liu, C., Zhang, D., \& Yang, Y. (2015). Comparison of geothermal with solar and wind power generation systems. Renewable and Sustainable Energy Reviews, 42, 1464-1474.

Lienau, P. J., \& Lunis, B. C. (1991). Geothermal direct use engineering and design guidebook. NASA STI/Recon Technical Report N, 92, 24030.

Lund, J. W. (2007b). Development and utilization of geothermal resources. In Proceedings of ISES World Congress 2007 (Vol. I-Vol. V) (pp. 87-95). Springer, Berlin, Heidelberg.

Lund, J. W., \& Boyd, T. L. (2016). Direct utilization of geothermal energy 2015 worldwide review. Geothermics, 60, 66-93.

Lund, J. W., \& Toth, A. N. (2020). Direct utilization of geothermal energy 2020 worldwide review. Geothermics, 101915.

Lund, J.W. (2007a). Characteristics, Development and Utilization of Geothermal Resources. Geo-Heat Center, Oregon Institute of Technology, pp. 1-9.

Maden Tetkik ve Arama Genel Müdürlüğü (MTA), 2021. Türkiye Jeotermal Enerji Potansiyeli ve Arama Çalışmaları. https://www.mta.gov.tr/v3.0/arastirmalar/jeotermal-enerjiarastirmalari. Erişim tarihi: 02.04.2021.

Melikoglu, M. (2017). Geothermal energy in Turkey and around the World: A review of the literature and an analysis based on Turkey's Vision 2023 energy targets. Renewable and Sustainable Energy Reviews, 76, 485-492.

Mertoglu, O., Simsek, S., Basarir, N., \& Paksoy, H. (2019, June). Geothermal energy use, country update for Turkey. In 
Proceedings of the European Geothermal Congress, Den Haag, The Netherlands (pp. 11-14).

Mundhenk, N., Huttenloch, P., Sanjuan, B., Kohl, T., Steger, H., \& Zorn, R. (2013). Corrosion and scaling as interrelated phenomena in an operating geothermal power plant. Corrosion Science, 70, 17-28.

Nogara, J., \& Zarrouk, S. J. (2018). Corrosion in geothermal environment: Part 1: Fluids and their impact. Renewable and Sustainable Energy Reviews, 82, 1333-1346.

Özbek, T. (2011). Jeotermal Kaynakların Sağlık ve Termal Turizmde Değerlendirilmesi. Jeofizik Bülteni, 68, 27-37.

Pambudi, N. A., Itoi, R., Yamashiro, R., Alam, B. Y. C. S., Tusara, L., Jalilinasrabady, S., \& Khasani, J. (2015). The behavior of silica in geothermal brine from Dieng geothermal power plant, Indonesia. Geothermics, 54, 109-114.

Pan, S. Y., Gao, M., Shah, K. J., Zheng, J., Pei, S. L., \& Chiang, P. C. (2019). Establishment of enhanced geothermal energy utilization plans: barriers and strategies. Renewable Energy, 132, 19-32.

Panagiotou, C. (1996). Geothermal greenhouse design. United Nations University. pp. 219-250.

Popovski, K. (2009). Agricultural and Industrial Uses of Geothermal Energy in Europe. International Geothermal Days Slovakia, Conference \& Summer School, CastáPapiernicka, Slovakia, Session III.1, p. 11, 2009.

Popovski, K., \& Vasilevska, S. P. (2003). Prospects and problems for geothermal use in agriculture in Europe. Geothermics, 32(4-6), 545-555.

Purnomo, B. J., \& Pichler, T. (2014). Geothermal systems on the island of Java, Indonesia. Journal of Volcanology and Geothermal Research, 285, 47-59.

Santos, J. J., Rodríguez, C. E., Carvalho, M., Barone, M. A., Palacio, J. C., \& Carrillo, R. A. (2018). Geothermal Power. In Advances in Renewable Energies and Power Technologies (pp. 173-205). Elsevier.

Shortall, R., Davidsdottir, B., \& Axelsson, G. (2015). Geothermal energy for sustainable development: A review of sustainability impacts and assessment frameworks. Renewable and sustainable energy reviews, 44, 391-406.

Soelaiman, T.A.F. (2016). Chapter 7-Geothermal Energy. Electric Renewable Energy Systems, 114-139.

Soltani, M., Kashkooli, F. M., Souri, M., Rafiei, B., Jabarifar, M., Gharali, K., \& Nathwani, J. S. (2021). Environmental, economic, and social impacts of geothermal energy systems. Renewable and Sustainable Energy Reviews, 140, 110750.

Sowizdzal, A. (2018). Geothermal energy resources in Polandoverview of the current state of knowledge. Renewable and Sustainable Energy Reviews, 82, 4020-4027.

Tester, J. W., Anderson, B. J., Batchelor, A. S., Blackwell, D. D., DiPippo, R., Drake, E. M., Garnish, Livesay, J., Moore, B., Nichols, M.C., Petty, K., Toksoz, S., \& Veatch, M.N.R.W. (2006). The future of geothermal energy. Massachusetts Institute of Technology, 358.

Toth, A., \& Bobok, E., Chapter 1-What Is Geothermal Energy? Flow and Heat Transfer in Geothermal Systems, pp. 1-19.

Towler, B.F. (2014). Chapter 11-Geothermal Energy. The Future of Energy, pp. 237-256.

Türkiye Elektrik İletim A.Ş. (TEİAŞ), 2021. Santral Kurulu Güç Raporlar1, Şubat 2021 Kurulu Güç Raporu. https://www.teias.gov.tr/tr-TR/kurulu-guc-raporlari Son Erişim Tarihi: 05.04.2021.
Türkiye Jeotermal Derneği (TJD), 2021. Dünya'da Jeotermal. http://www.jeotermaldernegi.org.tr/sayfalar-Dunya-daJeotermal. Son Erişim Tarihi: 02.04.2021.

Türkiye Sınai Kalkınma Bankası (TSKB) Enerji Bülteni, (2021). Aylık Enerji Bülteni Şubat 2021. https://www.tskb.com.tr/i/assets/document/pdf/enerjibulteni-subat-2021.pdf Son Erişim Tarihi: 04.04.2021.

Van den Heuvel, D. B., Gunnlaugsson, E., Gunnarsson, I., Stawski, T. M., Peacock, C. L., \& Benning, L. G. (2018). Understanding amorphous silica scaling under wellconstrained conditions inside geothermal pipelines. Geothermics, 76, 231-241.

Van Nguyen, M., Arason, S., Gissurarson, M., \& Pálsson, P. G. (2015). Uses of geothermal energy in food and agriculture. Opportunities for Developing Countries.

Vasquez, N. C., Bernardo, R. O., \& Cornelio, R. L. (1992). Industrial uses of geothermal energy a framework for application in a developing country. Geothermics, 21(5-6), 733-743.

Xia, L., \& Zhang, Y. (2019). An overview of world geothermal power generation and a case study on China-The resource and market perspective. Renewable and Sustainable Energy Reviews, 112, 411-423.

Yanar, P. (2015). Ege Bölgesi Jeotermal Sularında Lityum, Bor ve Arsenik Düzeylerinin İncelenmesi ve $\mathrm{Bu}$ Elementlerin Jeotermal Sulardan Seçimli Olarak Ayrılması. Ege Üniversitesi Fen Bilimleri Enstitüsü, Yüksek Lisans Tezi, $171 \mathrm{~s}$, İzmir.

Yavuz, E. (2010). Removal of Boron from Geothermal Waters by Reverse Osmosis Method. Ege University Graduate School of Applied and Natural Sciences, Master of Science Thesis, p. 134 , İzmir.

Y1lmaz-İpek, İ. (2009). Boron Removal from Geothermal Water by Ion Exchange-Membrane Filtration Hybrid Process. Ege University, Graduate School of Natural and Applied Sciences, Ph.D. Thesis, p. 268, İzmir. 